\title{
Drug- or toxin-induced pulmonary arterial hypertension
}

INSERM

\section{Source}

INSERM. (1999). Orphanet: an online rare disease and orphan drug data base. Drug- or toxin-induced pulmonary arterial hypertension. ORPHA:275786

Drug- or toxin-induced pulmonary arterial hypertension (PAH) is a form of pulmonary arterial hypertension (PAH, see this term) secondary to the exposition to drugs. Drug- or toxin-induced PAH is characterized by elevated pulmonary arterial resistance leading to right heart failure. Drug or toxin induced PAH is prog ressive and potentially fatal. 